\title{
Study of Calculation of Degaussing System for Reducing Magnetic Field from Submersible Vehicle
}

\author{
Sardono Sarwito ${ }^{1}$, Juniarko Prananda ${ }^{2}$, Eddy Setyo Koenhardono ${ }^{3}$, Anggela Wahyu Kurniawan ${ }^{4}$
}

\begin{abstract}
Indonesia are also increasingly taking the development of maritime technology, such as in a Submersible Vehicle one is degaussing system, this technology should be owned by the vessel so that the vessel can avoid dangerous explosive equipment contained in the sea. Degaussing system is a system that is in use on the metal parts or electronic devices that are at risk of a magnetic field. This system is used to prevent the vessel from dangerous equipment in the sea which can trigger an explosion and the damage that utilize magnetic fields as a metal-detection sensor when the boat was doing dives. To the authors will plan the design degaussing system, and calculating the system in order to reduce the magnetic properties of the Submersible Vehicle which were obtained by the use of Coil Degaussing along 214,5 meters, a diameter of 0,2, with 500.000 coil that will generate a current of 0,0157 Ampere's 0.0787 Tesla generates a magnetic field.
\end{abstract}

Keywords — magnet, degaussing, submersible vehicle

\section{INTRODUCTION}

I ndonesia, which has a vast ocean where the first ever in Indonesia invaded and used as the battlefield, so the rest of the war is still a lot left in the Indonesian ocean can harm submersible vehicle during a dive. The equipment is usually harmless, many are in the border area between countries and there are many dangerous equipment that enable them take advantage of the magnetic field. Therefore, Degaussing System is in need to eliminate the magnetic field that caused by electrical equipment which is in a submersible vehicle and the magnetic field produced by the Earth.

Degaussing System is a system designed to eliminate the magnetic field of the ship. With the application degaussing system on a submersible vehicle, the vehicleunders will be a vessel that has the ability to resist the detection of magnetic fields in the surrounding areas, whether the magnetic field emanating from the earth and the magnetic field generated by the equipment that might causing physical damage to the submersible vehicle while it underwater dives.

It is expected to use the system on a submersible vehicle degaussing will reduce the effects of magnetism on metal, so it will minimize the submersible vehicle hit completions - dangerous equipment that utilizes magnetic systems work as a trigger in the sea where the equipment causing damage to the side and other parts of ships.

Sardono Sarwito, Department of Marine Engineering, Institut Teknologi Sepuluh Nopember, Surabaya 60111, Indonesia, Email: sarsar@its.ac.id

Juniarko Prananda, Department of Marine Engineering, Institut Teknologi Sepuluh Nopember, Surabaya 60111, Indonesia, Email: juniarko.prananda@gmail.com

Eddy Setyo Koenhardono, Department of Marine Engineering, Institut Teknologi Sepuluh Nopember, Surabaya 60111, Indonesia, Email: eddy-koen@its.ac.id

Anggela Wahyu Kurniawan, Department of Marine Engineering, Institut Teknologi Sepuluh Nopember, Surabaya 60111, Indonesia, Email : awenk.x13@gmail.com
This study will be ease in the design calculation method of degaussing system on a submersible vehicle

\section{LITERATURE REVIEW}

The magnetic field is defined as the area (space) around the magnets are still influenced by the magnetic force.

An expert of Natural Sciences who is also a professor at the University of Copenhagen named Hans Christian Oersted (1777 - 1851) in his study has found that around electrical currents are the magnetic field. And concluded that:

a. In the vicinity there are a magnetic field electric current.

b. Direction of the magnetic field (lines of magnetic force) depends on the direction of the electric current

c. A large magnetic field is affected by the strong currents and the distance to the wire.

The influence of the magnetic field generated by a current conductor of the objects in the vicinity are very small. This is due to the magnetic field generated very little or week and get a strong field effect, the conductor must be rolled into a coil. At the coil, the magnetic field generated by the windings of the coil is reinforced by another. When the solenoid coil is long known.

When inside the coil by the soft iron core magnetism effect becomes much greater. Because the coils are wound on a soft iron core will create a powerful magnet. Influence the relationship between electric current and magnetic fields called electromagnetic or electrical magnets. It was first discovered by Hendrik Lorentz. Lorentz force occurs when electrical current carrying wires are inside a magnetic field. Large Lorentz force depends on a large magnetic field, conductor length, and large electric current flowing in the wires. For the direction of flow of electrical current perpendicular to the magnetic field direction, 
Toroid is a solenoid that is curved so that a circular coil. Is a toroidal coil consisting of $\mathrm{N}$ loops of wire that is shaped like a circle. With regard to wire compact, we can calculate the magnetic field inside the toroid, with the distance from the center point

Earth's magnetic field is the cause of a permanent magnetic field of the ship. The process of building a ship in the Earth's magnetic field to produce a sufficient amount of permanent-magnet sufficient in metal floating structure.

Whenever there is a movement of metal floating structure, lines of magnetic force also moves along with it. Movement of this magnetic stripes resulted in the addition or subtraction of Earth's magnetic field. And thus the boat floating down the momentum will create their own unique magnetic pins. This magnetic sign can be used to trigger equipment that are susceptible to magnetism. The same principle is used in warding off the enemy ships in the battle of magnetic mines mainly in production when it detects a magnetic sign.

induced magnetic field in the floating structure depends on the potential of Earth's magnetic field and the layout and direction of the floating structure w.r.t. Earth's magnetic field. As discussed previously, the magnetic induction vessel is also the cause of the magnetic field of permanent magnet vessels such as ships. Ships are usually large continuous floating structure counteract Earth's magnetic field. Whenever a conductor moving in a magnetic field, cutting the lines of magnetic flux. Therefore, the conductor induces a sufficient amount of tension in it. Such as the layout of the outside of the ship is not homogeneous in its structure, which is why the amount is different from the voltage inducted at various points on the body of the ship. This voltage difference causes the flow of current through the body of the ship. This in turn creates magnetism known as magnetic induction vessel.

Number of permanent magnetization in the vessel can be determined from the following:

- The strength of the magnetic lines of the earth around the area of ship building.

- The type of metal used for the construction of the ship's structure.

- Type of method used for the construction of the ship's structure.

- The layout and direction w.r.t. the ship's structure. The strength of Earth's magnetic lines during construction.

This induced magnetic field can be resolved into the following:

- Vertical field permanent Components

- Component permanent longitudinal field
- Permanent component field athwarship

Degaussing is a procedure to reduce the potential magnet.Proses degaussing field is used to protect ships from magnetic mines set up by enemy ships. Degaussing systems installed on board the vessel to reduce the effect on the earth's magnetic field, to achieve this, the magnetic field ship "zeroised" by controlling the electric current flowing through the degaussing coil in the right location in the hull. This, in time, reduce the residual magnetism ship because Earth's magnetic field.

Degaussing ship installation consists of installing permanent degaussing coil, a control unit for controlling the coil current, and compass compensating equipment to prevent the disruption of magnetic compasses by the magnetic field of the degaussing coil. The following types of coils that is found on the installation degaussing.

Degaussing is a procedure to reduce the potential magnet.Proses degaussing field is used to protect ships from magnetic mines set up by enemy ships. Degaussing systems installed on board the vessel to reduce the effect on the earth's magnetic field, to achieve this, the magnetic field ship "zeroised" by controlling the electric current flowing through the degaussing coil in the right location in the hull. This, in time, reduce the residual magnetism ship because Earth's magnetic field.

Degaussing ship installation consists of installing permanent degaussing coil, a control unit for controlling the coil current, and compass compensating equipment to prevent the disruption of magnetic compasses by the magnetic field of the degaussing coil. The following types of coils that is found on the installation degaussing.

- The primary coil (M): $M$ compensating coil induction vertical component of the magnetic field and the permanent ship (zone Z). It is installed in the horizontal plane on the water surface

- Permanent Forecastle - Quarterdeck permanent coil (FP-QP). FP-compensating coil QP permanent component longitudinal magnetic field of the ship. FP coil surrounds about $1 / 4$ of the front part of the ship in a horizontal plane on the main deck. QP coil surrounds about $1 / 4$ the back of the boat in a horizontal plane on the deck

- Induction Forecastle, Induction coils Quarterdeck (FI-QI) situated in the same area with the coil FP$\mathrm{QP}$, they compensate for the component of the magnetic field induction elongated vessel

- Athwartship coil (A) mounted on a vertical plane and extends from keel to main deck. This compensates athwartship component induction and permanent component of the magnetic field athwartship ship 


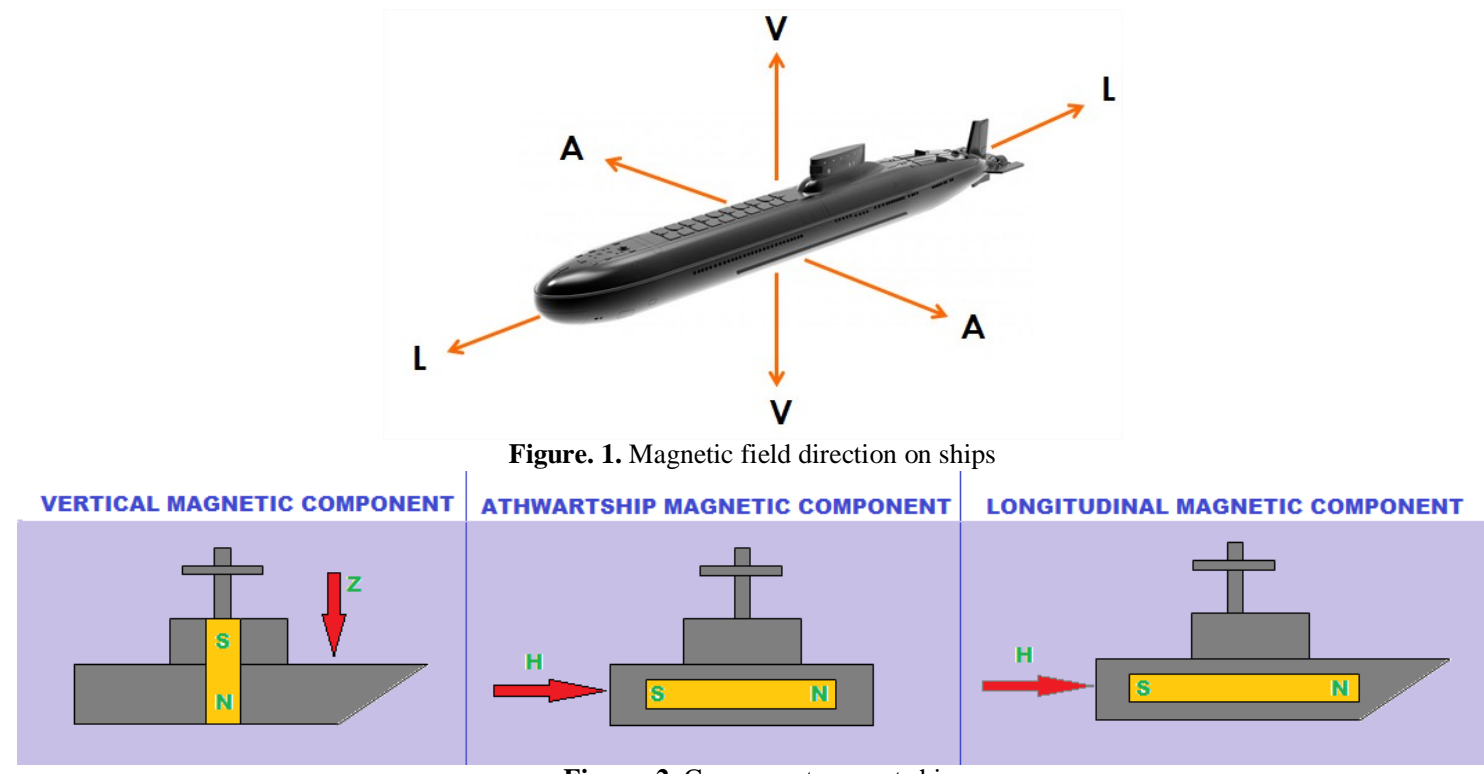

Figure. 2. Component magnet ships
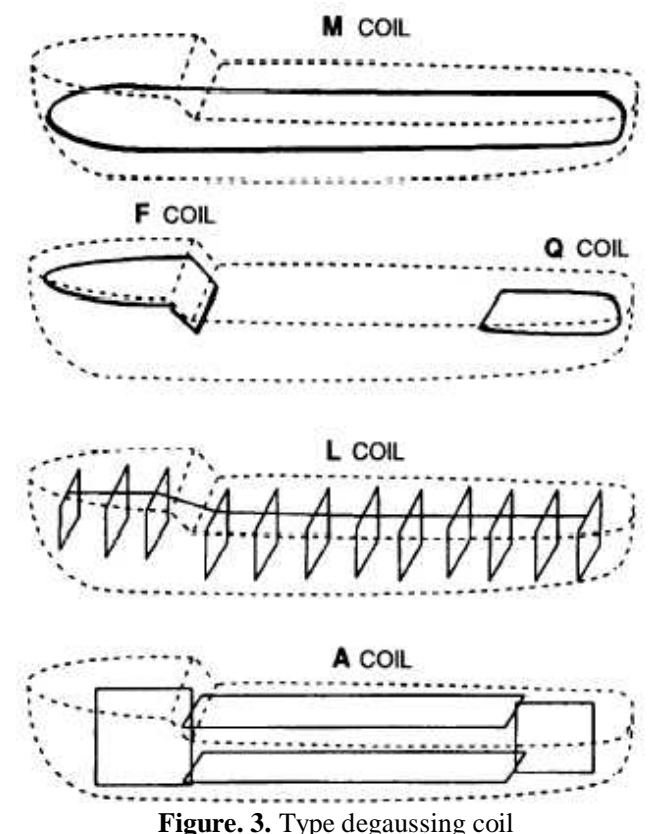

Figure. 3. Type degaussing coil

\section{RESEARCH METHODOLOGY}

The methodology is a step goal-setting and final project. Metodeologi serves as the main framework to be the determining step and discussion. The method used in this final project is the calculation of degaussing systems. The steps - steps in the methodology of construction of this Final Project, among others: (1) Identification and Problem Formulation (2) Looking for Data and Study Literature (3) Data Collection (4) Calculation System (5) Data Analysis. (6) Conclution and Sugestion

\subsection{Identification and Problem Formulation}

Identification and formulation of the problem is the first step in working out the final task to find the right problems to be appointed as the final project and provide solutions so that the final project was done bias also helpful to related parties.

\subsection{Literature Study}

Literature is the next step in the final project to look for references and materials to be used as reference material in accordance with the analysis that is reliable so as to help the final project. The literature study can be taken from a reference source document or Data Operations, Engineering Books, Catalogs and related Journal.

\subsection{Data Collection}

The data collection is the next step as a raw material of the data required for the final project. The data collection is very important that the final project referring to the data we have acquired. The collection of data must be of a concrete source. The data collection includes: Text Book submarine

\subsection{Calculation System}


Of Data Design / Draft previous Design and Operational Requirement, to do the calculation system. Where the calculation of this system include:

a) The calculation of the Earth's Magnetic Field

b) The calculation of the magnetic field generated by submarine

c) Calculation of Magnetic Field on the caused by the electrical equipment on submarines

d) Calculation of Coil

e) Calculation of weight Component Degaussing System.

\subsection{Data Analysis}

Analysis of the data used to identify the data used in this final project is appropriate and correct or that the results of this thesis can be made as references and materials to make other improvements.

\subsection{Conclution and Suggestion}

Conclusions and Recommendations are made based on all aspects of the discussion of this thesis.

\section{RESULTS AND DISCUSSION}

\subsection{Earth Magnetic Field}

Variations in Earth's Magnetic Field is is 0:25 Gauss 0.65 Gauss or nanotesla 25,000 - 65,000 nanotesla. And large magnetic fields contained in the territorial waters of Indonesia is 35000-50000 nanotesla.

\subsection{Magnetic Field from Electrical Equipment on} Submarine

The magnetic field is not only caused by the earth's magnetic, but the equipment of electricity also produces electricity, which is different on each apparatus, with calculating the magnetic field that caused by the vessels existing electric submarine will assist in the design of system degaussing more accurate and more optimal. is the calculation of existing electrical equipment on submarines

The main specifications of electrical equipment on submarines:

\section{Generator \\ Artificial : : Anton Piller Germany \\ Type : NTB 10-1222 \\ Capacity $\quad: 4 \times 420 \mathrm{~kW}$ \\ Output voltage : 180 Volt - 340 Volt}

2. Motor Drivers Principal

$\begin{array}{ll}\text { Artificial } & \text { : Siemens Germany } \\ \text { Type } & : \text { VG.489/50-12 } \\ \text { Capacity } & : 2 \times 1850 \mathrm{~kW}\end{array}$

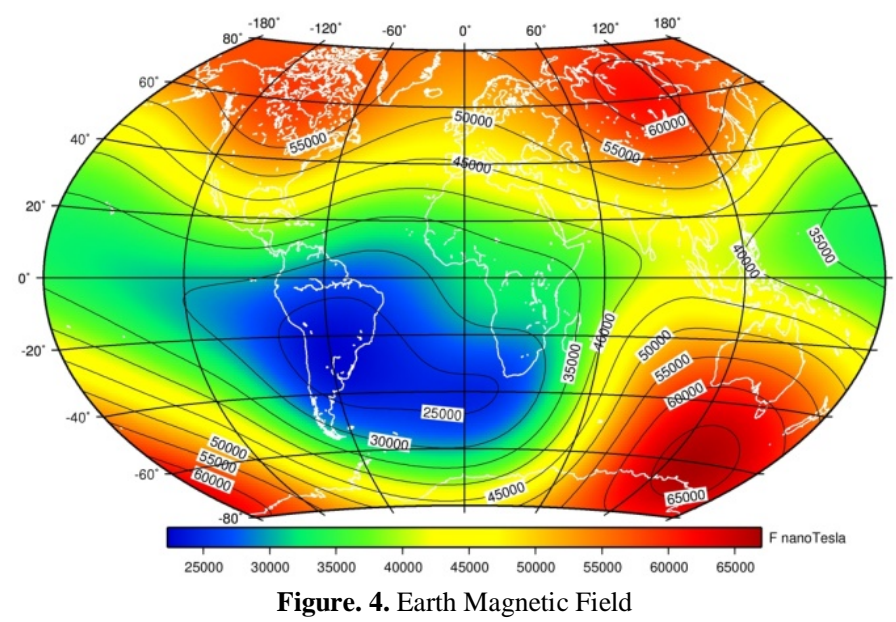

To search for existing magnetic field on electrical equipment can use the formula

\section{Current in Main Driver Motor}

$$
\begin{aligned}
& I=2100 \text { Ampere (data in specification catalouge) } \\
& 2 \times 2100=4200 \text { Ampere }
\end{aligned}
$$

3. Other electrical equipment available on submersible for $10 \%$ of the total amount of current to Generator and Main Driver Motor

$$
\begin{aligned}
& =10 \% \times(\mathrm{A}+42002023.12 \mathrm{~A}) \\
& =10 \% \times 6223.12 \mathrm{~A} \\
& =622.31 \mathrm{~A}
\end{aligned}
$$


Total current flowing in the main electrical equipment submersible are:

2023,12 A + $4200 \mathrm{~A}+622,31=6845,432$ Ampere

Magnetic fields on electrical equipment

$B=4 \pi \times 10^{-7} . I$

1. Magnetic Field Generator

$$
\begin{aligned}
\mathrm{B} & =4 \pi \times 10-7 . \mathrm{I} \\
& =4 \times 3.14 \times 10-7 \times 2023.12 \\
& =0.002541039 \text { Tesla }
\end{aligned}
$$

2. Magnetic Field in Main Driver Motor

$$
\begin{aligned}
\mathrm{B} & =4 \pi \times 10-7 . \mathrm{I} \\
& =4 \times 3.14 \times 10-7 \times 4200 \\
& =0.0052752 \text { Tesla }
\end{aligned}
$$

3. Magnetic Field in other submersible Equipment

$$
\begin{aligned}
\mathrm{B} & =4 \pi \times 10-7 . \mathrm{I} \\
& =4 \times 3.14 \times 10-7 \times 622.31 \\
& =0.0007816 \text { Tesla }
\end{aligned}
$$

Total magnetic field flows in the main electrical equipment submersible are:

$$
0.0025+0.0053+0.0008=0.0086 \text { Tesla }
$$

So Total Magnetic Field that of the submarine is

$$
0.0086+0.00005=0.00865 \text { Tesla }
$$

\subsection{Current Calculation for degaussing System}

Degaussing system current requirement to use a working system of the toroidal where we calculate the material requirements -material the degaussing system by using the following formula:

$$
\mathrm{B}=\frac{\mu_{0} \mathrm{NI}}{2 \pi \mathbf{a}}
$$

if Coil Diameter (a) and the amount of coil (N) varied

$\mathrm{a}=0.2 \mathrm{~m} / 0.3 \mathrm{~m} / 0.4 \mathrm{~m}$ (Variation Diameter) $\mathrm{N}=500,000 / 600,000 / 700,000 / 800.000 / 900,000$ (Variation winding)

So,

$$
I=\frac{B .2 \pi a}{\mu_{0 .} \mathrm{N}}
$$

The current flowing in the coil's diameter variation and windings in table 1 :

TABLE 1

CURRENT FLOWING IN THE COIL'S DIAMETER VARIATION AND WINDINGS

\begin{tabular}{cccc}
\hline Diameter & 0.2 & 0.3 & 0.4 \\
\hline Windings & 0.01574 & 0.02361 & 0.03148 \\
\cline { 1 - 3 } 500.000 & 0.013117 & 0.019675 & 0.026233 \\
\hline 700.000 & 0.011243 & 0.016864 & 0.022486 \\
\hline 800.000 & 0.0098375 & 0.0147563 & 0.019675 \\
\hline 900.000 & 0.008744 & 0.013117 & 0.017489 \\
\hline
\end{tabular}

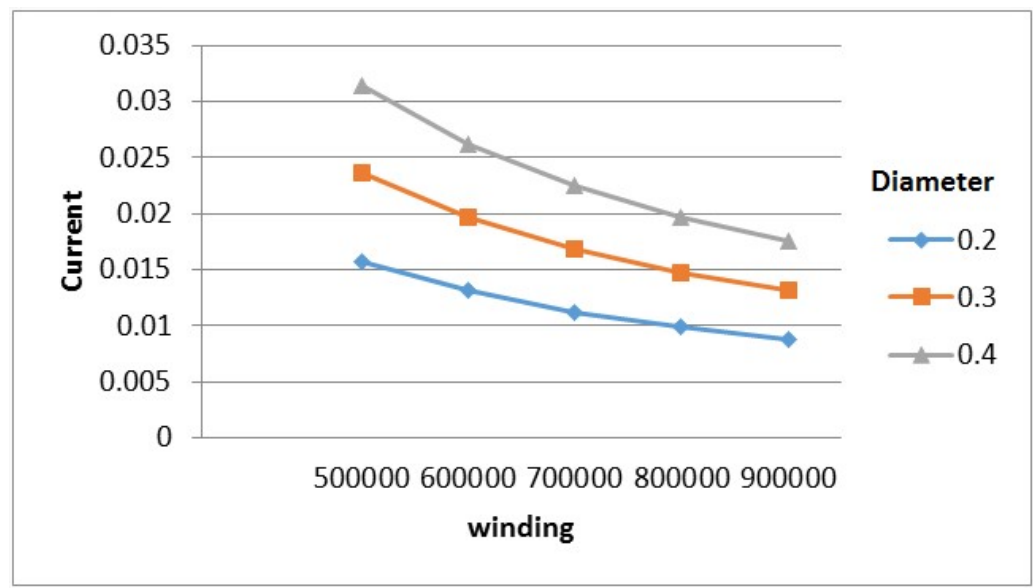

Figure. 5. current flowing in the coil's diameter variation and windings

From the results of calculations performed to determine the currents generated by the variation of the diameter of the coil and the number of loops in use, can be in the know that the tables and graphs show that: 
1. The function of the number of windings is inversely proportional to the size of the diameter of coil used.

2. The more coils in use, the smaller the amount of current generated.

3. The larger the diameter of the coil that is in use, the greater the current generated.

Therefore, to determine how many turns how large a diameter that is in use. There are the factors that should also be noticed, namely:

1. Raw Material Price: the more winding and the larger diameter that is in use the more expensive meal also cost raw materials of manufacture.

2. Weight Installation: the more winding and the larger diameter in use ate the greater the mass produced, and weight gain in vehicle-unders are very berpengarus once in the stability of the ship.

3. Power Consumption: the greater the current generated is also an effect on the electrical energy consumption, minimize the use of electrical energy in a vehicle submerged ship very into account to maximize the operation of a ship.

4. Installation System: ease of installation degaussing system also need to be noticed, because the embedded space in the vehicle is very limited and the use of space in it are concerned the location and security, in addition to be easy to maintain.

5. Availability of raw materials: The last thing no less important is the availability of raw materials, so that when the construction of the installation of the system is not constrained by the lack of raw materials, out of stock as well as the difficulty in finding parts when performing repair and maintenance degaussing systems.

Based on the assessment of the above factors, is determined to a diameter that is in use on the degaussing system is 0.2 meters and for the number of loops that will be used are as many as 500,000 windings. With the results of the analysis that:

- By using a small quantity of the purchase price of materials will eat small

- Using a little material so heavy that produced will be slight.

- By using a small quantity of the installation and use of space in the vehicle-unders will be more efficient

- For the electrical energy consumption is not too big.

\subsection{Calculation of Core Coil Degaussing}

The calculation of core coil is needed for vehicleunders are referring to the dimensions of the ship itself, because the core of this coil will be installed around the ship according to the shape of the ship, and the following are the details of coil core needs:

Ship Dimensions:
LOA (P)

Diameter in the vessel (D)
: 59.57 meters

: 6.2 meters

$$
\begin{aligned}
\text { - F Coil } & =2 \times(14.54+6.2) \\
& =41.48 \text { meters } \\
\text { - Q Coil } & =2 \times(14.54+6.2) \\
& =41.48 \text { meters }
\end{aligned}
$$

The total length of the core coil mounted on a submersible are:

$$
131.54+41.48+41.48=214.5 \text { meters }
$$

\subsection{Length Degaussing Cooper wire Calculation}

Copper wire length calculation on degassing installation is as follows:

Data input :

Number of windings $\quad: 500,000$ windings

Core Coil Diameter $\quad: 0.2$ meters

Thus, the length of copper wire is needed is

$=$ Diameter Core Coil x Number of windings

$=0.2 \times 500,000$

$=100,000$ meters

4.6 Diameter Degaussing Cooper wire Calculation

Of calculation - the previous calculation, the calculation degaussing diameter copper wire can be calculated as follows.

Data input :

Number of windings $\quad: 500,000$ windings

Coil Core Length $\quad: 214.5$ meters

Thus, the required diameter is

$=$ Length Core Coil

number of windings

$=2.145 .000 \mathrm{~mm}=0.429 \mathrm{~mm} / \approx 0.43 \mathrm{~mm}$

500,000

So diameter copper wire that is required at this degaussing installation is $0,43 \mathrm{~mm}$.

4.7 Weight Instalation Degaussing System Calculation

From the result of the previous calculation can know the weight of the degaussing system components:

1. Degaussing Switch Board (Based Specification Tool) Weighs: $389 \mathrm{Kg}$

2. Core Coil

$$
\begin{aligned}
& \text { Heavy Core Coil = Area Core Coil } \mathrm{x} \text { Iron Density } \\
& =\Pi \mathrm{r} 2 \mathrm{t} x \mathrm{x} \text { Iron } \\
& =3.14 \times(0.1) 2 \times 214.5 \times 7.86 \\
& =52.939 \mathrm{Kg} / \approx 52.94 \mathrm{Kg}
\end{aligned}
$$

So the total weight of degasussing installation of this system are:

$$
52.94 \mathrm{~kg}+389 \mathrm{~kg}+0.49 \mathrm{~kg}=442.43 \mathrm{~kg}
$$




\subsection{Degaussing Instalation}

Installation Degaussing System mounted on a vehicle submerged in the show by Figure 6. Degaussing System Wiring Diagram, these images show the installation details $\mathrm{M}$ coil, $\mathrm{F}$ coil and coil Q, as well as the scheme of power supply to the power supplay degaussing coil.

On installation of coils in shape and is connected to the required shape according to the size has been calculated. Zones in each region cruise determine the difference in the amount of current needed by degaussing although there is little difference, but it is needed for the accuracy of the system. Flow is needed in the set by rheostats to adjust the size of the current to be piped to the degaussing coil. Figure 6. illustrates the control system of the installation degaussing to $\mathrm{M}, \mathrm{M}$, and $\mathrm{Q}$ coils.the A-coil is not used here because of the level of protection you want does not require the existence of a coil, however, the controls will be similar to coil FI-QI. In this picture the general arrangement $\mathrm{F}$ and $\mathrm{Q}$ coil splitting into separate FI-QI and FP-QP circuit. FI-circuit QI neutralize longitudinal magnetic field induction only when the circuit-QP FP works to neutralize the permanent magnetic field longitudinal. The polarity of the current in-FI and FP-QP QI adjusted by regulating coil commutator switch.

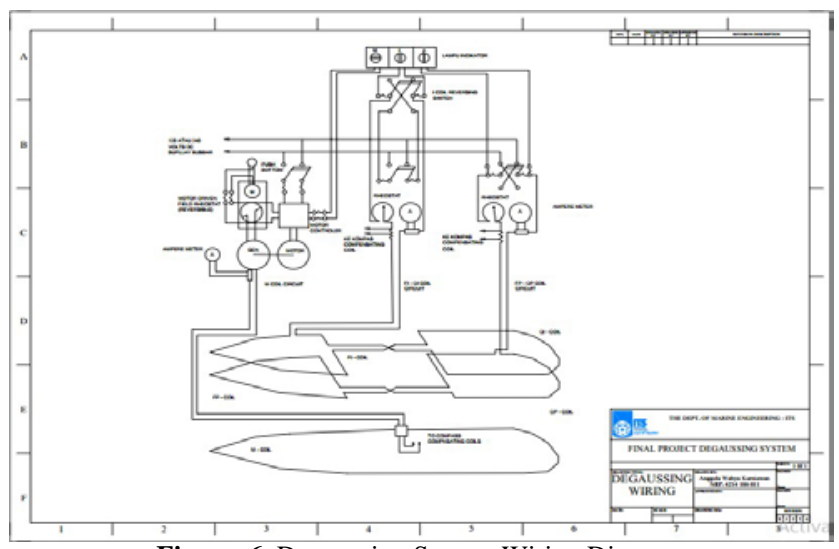

Figure. 6. Degaussing System Wiring Diagram

In M-coil, low voltage power supplied from the motor-generator sets. And the polarity of the output current generator adapted to a motor operated by a rheostat circuit gave the command to reverse the current generation field.

To eliminate the effects of deviation which is caused by a compass that can cause deviation effect on this system compass deviation degaussing coil mounted in a prefabricated compensation binnacles and fed to eliminate interference with the degaussing coil. By adjusting the resistor, the current in the coil compensated compass is set to neutralize the effect of degaussing coil on a compass needle. After this adjustment is made, the current compensation will vary as degaussing current and automatically generate the correct compensation for all the current degaussing.

\section{CONCLUSION}

From calculations that have been done in this final project can be summed up as follows:

1. Calculation of Degaussing System on a vehicle submerged produce Magnetic Field Amounting 0.00865 Tesla $(\mathrm{T})$ and the magnitude of the magnetic field that produced a very effective way to remove magnetism on the ship that caused by electrical appliances that give rise to electric and magnetic fields of the earth at 0.00865 Tesla

2. Technical Requirements for installation design degaussing current system is in use at 0.01574 Ampere, with the number of coil windings 500,000, the main coil length of 214.5 meters with a diameter of 0.2 meters consists of 131.54 meters to M Coil , 41.48 to 41.48 for the F Coil and Coil Q. So that the entire weight of the install in installation on ships is $442.43 \mathrm{Kg}$

\section{AKNOWLEDGEMENTS}

Author Anggela Wahyu Kurniawan would like to say thanks to Supervisor 1 Mr. Juniarko Prananda, ST.,MT. and Supervisor 2 Mr. Ir. Sardono Sarwito, M.Sc. and Head of Department of Marine Engineering - ITS Surabaya who had given all facilities at campus to finish this Final Project

\section{REFERENCES}

[1] Nicholas B.Michel 1948. Shipboard Degaussing "Installations for Protection Against Magnetic Mines”.

[2] Shengdao Liu, Guohua Zhou, Changhan Xiao, Daming Liu, 2009." The Study on the Deployment Regions of Magnetic Sensors in the Closed Loop Degaussing System for Double Hull Submarines.” College of Electrical and Information Engineering Naval University of Engineering Wuhan, China.

[3] Bob Gordon, 1984. “The demagnetisation of ships”. England.

[4]. Raveendra Varma, R A. 2014. "Design of Degaussing ystem and Demonstration of Signature Reduction on Ship Model through Laboratory Experiments”. Naval Science and Technological Laboratory (NSTL), DRDO, Visakhapatnam, India

[5] I. S. FRASER, B.Sc, A. A. READ,* and B. E. VIEYRA, B.Sc. 1945."The Electrical Engineering Aspect of Degaussing”

[6] Jacob T. Kephart, Brian K. Fitzpatrick, Peter Ferrara, hael Pyryt, Jules Pienkos, and E. Michael Golda. 2011. “ High Temperature Superconducting Degaussing From Feasibility Study to Fleet Adoption”.

[7] Gossage, R. J. B.Sc. 1946, “ The Use Of Ship Models Magnetically To Scale In Degaussing Research.” 
International Journal of Marine Engineering Innovation and Research, Vol. 1(2), Mar. 2017. 68-75

(pISSN: 2541-5972, eISSN: 2548-1479)

[8] Potts, W. C., M.Sc, F.Inst.P. 1946. "The Magnetic Field of a Ship and its Neuralization by Coil Degaussing”

[9] I. S. Fraser, B.Sc, Associate Member,* A. A. Read,* and

[10] B. E. Vieyra, B.Sc, Associate Member, 1946' “The Electrical Engineering Aspect of Degaussing”

[11] R. A. Robinson, 1948. "Compensation of Effects of Degaussing Coils on Shipboard Magnetic Compasses by Use Compass-Compensating Coils.”

[12] Nak-Sun Choi, Giwoo Jeung, Chang-Seob Yang, Hyun-Ju Chung, and Dong-Hun Kim. 2012. "Optimization of Degaussing Coil Currents for Magnetic Silencing of a Ship Taking the Ferromagnetic Hull Effect Into Account”', IEEE Transaction of Applied Superconductivity

[13] http://fisikazone.com/hukum-coulomb/[diakses tahun 2016]

[14] https://belajar.kemdikbud.go.id/SumberBelajar/ tampilajar. php?ver=11\&idmateri=355\&mnu=Materi5\&kl=12 [diakses tahun 2016]

[15] http://www.berpendidikan.com/2015/10/medan-magnetdisekitar-arus-listrik.html[diakses tahun 2016]

[16] https://artikelnesia.com/2012/09/18/medan-magnet-di-sekitarkawat-berarus-listrik/[diakses tahun 2016]

[17] http://www.gatewan.com/2015/12/mengenal-hukum auss.html [diakses tahun 2016]

[18] http://siskamahabbahislam.blogspot.co.id/2014/03/fliks-istrikdan-hukum-gauss.html [diakses tahun 2016]

[19] electricalfundablog.com/blog/ [diakses tahun 2016]

[20] http://navyadministration.tpub.com/14220/css/The-hipboardDegaussing-System-66.htm [diakses tahun 2016] [21]http://fas.org/man/dod-101/navy/docs/swos/eng/62B-303. html[diakses tahun 2016]

[22] https://en.wikipedia.org/wiki/Naval_mine[diakses tahun 2016] 